NASA/TM-2002-211798

Fan Noise Source Diagnostic Test Computation of Rotor Wake Turbulence Noise

M. Nallasamy

QSS Group, Inc., Cleveland, Ohio

E. Envia and S.A. Thorp

Glenn Research Center, Cleveland, Ohio

A. Shabbir

University of Toledo, Toledo, Ohio 
Since its founding, NASA has been dedicated to the advancement of aeronautics and space science. The NASA Scientific and Technical Information (STI) Program Office plays a key part in helping NASA maintain this important role.

The NASA STI Program Office is operated by Langley Research Center, the Lead Center for NASA's scientific and technical information. The NASA STI Program Office provides access to the NASA STI Database, the largest collection of aeronautical and space science STI in the world. The Program Office is also NASA's institutional mechanism for disseminating the results of its research and development activities. These results are published by NASA in the NASA STI Report Series, which includes the following report types:

- $\quad$ TECHNICAL PUBLICATION. Reports of completed research or a major significant phase of research that present the results of NASA programs and include extensive data or theoretical analysis. Includes compilations of significant scientific and technical data and information deemed to be of continuing reference value. NASA's counterpart of peerreviewed formal professional papers but has less stringent limitations on manuscript length and extent of graphic presentations.

- TECHNICAL MEMORANDUM. Scientific and technical findings that are preliminary or of specialized interest, e.g., quick release reports, working papers, and bibliographies that contain minimal annotation. Does not contain extensive analysis.

- CONTRACTOR REPORT. Scientific and technical findings by NASA-sponsored contractors and grantees.
- CONFERENCE PUBLICATION. Collected papers from scientific and technical conferences, symposia, seminars, or other meetings sponsored or cosponsored by NASA.

- SPECIAL PUBLICATION. Scientific, technical, or historical information from NASA programs, projects, and missions, often concerned with subjects having substantial public interest.

- TECHNICAL TRANSLATION. Englishlanguage translations of foreign scientific and technical material pertinent to NASA's mission.

Specialized services that complement the STI Program Office's diverse offerings include creating custom thesauri, building customized data bases, organizing and publishing research results ... even providing videos.

For more information about the NASA STI Program Office, see the following:

- Access the NASA STI Program Home Page at http://www.sti.nasa.gov

- E-mail your question via the Internet to help@sti.nasa.gov

- Fax your question to the NASA Access Help Desk at 301-621-0134

- Telephone the NASA Access Help Desk at 301-621-0390

- Write to:

NASA Access Help Desk

NASA Center for AeroSpace Information 7121 Standard Drive

Hanover, MD 21076 
NASA/TM-2002-211798

AIAA-2002-2489

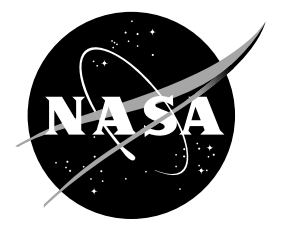

\title{
Fan Noise Source Diagnostic Test Computation of Rotor Wake Turbulence Noise
}

\author{
M. Nallasamy \\ QSS Group, Inc., Cleveland, Ohio \\ E. Envia and S.A. Thorp \\ Glenn Research Center, Cleveland, Ohio
}

\author{
A. Shabbir \\ University of Toledo, Toledo, Ohio
}

Prepared for the

Eighth Aeroacoustics Conference

cosponsored by the American Institute of Aeronautics and Astronautics and the Confederation of European Aerospace Societies

Breckenridge, Colorado, June 17-19, 2002

National Aeronautics and

Space Administration

Glenn Research Center 


\section{Acknowledgments}

The authors wish to acknowledge the help and support of many colleagues who contributed to this work. In particular, we would like to thank Tim Beach, John Gallagher, Mark Celestina, Richard Mulac, Vijay Garg, John Admaczyk, and Richard Woodward.

Available from

NASA Center for Aerospace Information 7121 Standard Drive

Hanover, MD 21076
National Technical Information Service 5285 Port Royal Road Springfield, VA 22100 


\title{
Fan Noise Source Diagnostic Test COMPUTATION OF Rotor WAKE TURBUlEnCE NoISE
}

\author{
M. Nallasamy \\ QSS Group, Inc. \\ Cleveland, Ohio 44135 \\ E. Envia and S.A. Thorp \\ National Aeronautics and Space Administration \\ Glenn Research Center \\ Cleveland, Ohio 44135 \\ A. Shabbir \\ University of Toledo \\ Toledo, Ohio 43606
}

\begin{abstract}
An important source mechanism of fan broadband noise is the interaction of rotor wake turbulence with the fan outlet guide vanes. A broadband noise model that utilizes computed rotor flow turbulence from a RANS code is used to predict fan broadband noise spectra. The noise model is employed to examine the broadband noise characteristics of the 22-inch Source Diagnostic Test fan rig for which broadband noise data were obtained in wind tunnel tests at the NASA Glenn Research Center. A 9-case matrix of three outlet guide vane configurations at three representative fan tip speeds are considered. For all cases inlet and exhaust acoustic power spectra are computed and compared with the measured spectra where possible. In general, the acoustic power levels and shape of the predicted spectra are in good agreement with the measured data. The predicted spectra show the experimentally observed trends with fan tip speed, vane count and vane sweep. The results also demonstrate the validity of using CFD-based turbulence information for fan broadband noise calculations.
\end{abstract}

\section{INTRODUCTION}

Owing to the success of fan tone noise reduction techniques [1], fan broadband noise is now widely acknowledged as the next major obstacle to be overcome in attempts to reduce aircraft engine noise. But, unlike tone noise, the sources of fan broadband noise are many and most are not as well understood. In response to this challenge a number of theories [2-5] have been devised to help elucidate the nature and characteristics of fan broadband noise. These theories require flow turbulence characteristics (i.e., spectrum, intensity, length scales, etc.) as input for computing noise spectra. Typically, such information is available from an experiment [6] or is simply guessed at to provide the best fit of the predicted noise spectra to the measured ones. An alternative approach is to compute the turbulence characteristics using a Reynolds-Averaged NavierStokes (RANS) type calculation, since that would provide a true prediction capability.

This paper presents one such attempt that combines predicted flow turbulence characteristics obtained from a turbomachinery CFD code with a 
fan broadband noise theory to compute fan noise spectra. The flow code, called APNASA [7], is a three-dimensional Navier-Stokes solver with an improved $k-\varepsilon$ turbulence model [8]. The noise code is a revised and enhanced version of an analytical noise prediction theory originally developed by Ventres et al. [9]. The testbed is a $1 / 5$-scale model of a representative high bypass ratio turbofan engine for which extensive aerodynamic and acoustic data were obtained [1012]. Only the broadband noise produced by the interaction of fan wake turbulence with the stator outlet guide vanes $(\mathrm{OGV})$ will be considered here. The data theory comparisons will be done on an acoustic power basis since the noise theory furnishes acoustic power predictions only.

The 22-inch diameter model fan was tested in the NASA Glenn Research Center's $9^{\prime} \times 15^{\prime}$ acoustic wind tunnel. The fan has 22 blades and a design tip speed of $1215 \mathrm{ft} / \mathrm{sec}$. The baseline OGV has 54 radial vanes and represents a conventional "cut-off" stator design (i.e., the blade passing frequency is cut off). The low-count OGV is a "cut-on" concept which has only 26 radial vanes but has the same solidity as the baseline stator. The smaller vane count was selected to reduce broadband noise [13]. The swept OGV has 26 swept vanes (with 30 degree sweep) and was designed to minimize the blade passing frequency tone penalty associated with a cut-on design.

The aerodynamic and acoustic tests were conducted over a wide range of fan operating conditions for each of the three OGV packs. For the purposes of the current work, however, only the speeds corresponding to the noise certification points will be discussed. The relevant fan operating conditions are listed in Table 1.

\begin{tabular}{|c|c|c|}
\hline $\begin{array}{c}\text { Power } \\
\text { Setting }\end{array}$ & $\begin{array}{c}\text { Corrected } \\
\text { Fan rpm }\end{array}$ & $\begin{array}{c}\text { Corrected Fan } \\
\text { Tip Speed, fps }\end{array}$ \\
\hline Approach & 7,808 & 750 \\
\hline Cutback & 11,074 & 1,060 \\
\hline Takeoff & 12,656 & 1,215 \\
\hline
\end{tabular}

Table 1: Fan operating conditions of interest.

In what follows, a summary of the analysis tools used in this work will be presented followed by a discussion of the theoretical results and their comparison with measured data (where possible). The paper concludes with a summary of important results.

\section{ANALYSIS}

The input for the noise prediction was generated by means of a series of CFD simulations of the fan rotor coupled with the fan outlet guide vane. The code used to generate the fan flow field is APNASA (see Ref. 7), which solves for the time average flow field in a typical passage of a blade row embedded within a multistage turbomachine. The simulations are three-dimensional and include the effect of viscosity. A modified $k-\varepsilon$ turbulence model (see Ref. 8) was used to account for the effect of turbulence mixing. However, before these CFD simulation could be undertaken it was necessary to establish the fan rotor geometry at tests conditions.

\section{Fan Running (Hot) Shape}

Fan rotors un-twist as they are run-up in rotational speed. It is well known that the effect of rotation on fan rotor shape has a non-trivial impact on aerodynamic performance. Thus, any CFD simulation of the fan rotor based on fan geometry other than the running geometry would be pointless. For the present study the chosen fan operating conditions included off-design conditions. Thus, a structural analysis was undertaken to determine the fan shape at the conditions corresponding to those of the test matrix. This analysis was conducted using the SABER [14] coupled aero/structural analysis system. An outline of the SABER system is presented in Figure 1. Starting with the fan rotor shape as manufactured (CAD geometry definition of the cold shape) the SABER system generates input for a structural analysis code. Included in the input is the rotational speed of the fan rotor.

Output from the structural analysis code is post-processed to generate a flow field grid for a CFD simulation. The output of the CFD simulation is post-processed by SABER to yield the pressure and temperature distribution on the fan rotor surface. This information is supplied to the 
structural analysis pre-processor, which then updates the input information to the structural analysis code and the cycle repeated until convergence (i.e., no significant change in fan rotor geometry) is obtained.

The transfer of information between the various elements of SABER is by means of NIGES and GGA files. The surface definition of fan rotor geometry, pressure and temperature distribution is in the form of NURBS [15-17].

The fan rotor geometry is established at running conditions (hot shape) along with its flow field upon convergence of this iterative process. Upon convergence of the iterative cycle within SABER the output takes full account of centrifugal loading, loading due to aerodynamic forces, and the temperature imposed on the fan rotor by the flow field.

The execution of SABER parallels the process used in a fan rotor mechanical design. A total of three coupled structural aero analysis were executed corresponding to the tip speeds of interest (i.e., the approach, cutback and takeoff conditions).

Using the computed fan hot shapes, fan speed lines (constant corrected speed) were established using APNASA for the nine $(3$ speeds $\times 3 \mathrm{OGV})$ test cases.

\section{$\underline{\text { Rotor Flowfield }}$}

The CFD grid has 407 grid cells in the axial direction, 51 grid cells in the radial direction and 51 grid cells in the azimuthal direction. Two views of the grid used in the flowfield simulations are shown in Figures 2 and 3. Figure 2 shows the meridional grid definition where locations of the fan rotor and outlet guide vane are noted. Figure 3 shows the fan rotor blade-to-blade grid layout at midspan. The streamline grid plane was designed to nearly coincide with the trajectory of the rotor wake in order to reduce numerical diffusion of the fan wakes.

Figure 4 shows the computed axial velocity field associated with the rotor at $75 \%$ of span at the takeoff condition. The wakes are well defined all the way to the leading edge plane of the outlet guide vane. Figure 5 shows the corresponding distribution of turbulent kinetic energy. It too is well defined to the leading edge plane of the outlet guide vane.

Figure 6 shows a comparison of the CFD results for the baseline configuration compared to data at the takeoff condition (see Ref. 6). The plots show the comparisons for an axial location 2 inches downstream of the rotor trailing edge (at the tip). Shown are the time averaged axial velocity, absolute tangential velocity and a measure of the intensity of the turbulent field. The agreement between the computed results and the corresponding measured results is good. The agreement extends to the end-wall region and includes the region of flow associated with the fan rotor tip clearance flow.

The turbulence intensity and length scale derived from the CFD simulations at the stator leading edge were used to estimate the frequency spectrum of the turbulent field impinging on the outlet guide vane. This information and the time average flow field of the outlet guide vane formed the input to the acoustic predictions. It should be noted that the input was used "as is" and no adjustments were made to the input to achieve a better agreement with data.

\section{$\underline{\text { Rotor Wake Turbulence - Stator Noise Model }}$}

The fan broadband noise prediction model used for this study is based on a theory developed by Ventres et al. (see Ref. 9). However, significant corrections, revisions and enhancement were made to the theory and a new code was written to take full advantage of the flow turbulence information available from the APNASA solutions. Details of the modified theory and the associated computer code will be reported in a future paper. Here, only salient features of the noise model are presented.

Predicated on a modal description of the noise field inside the fan duct, the theoretical model relates the expected values of modal acoustic power levels to the expected values of the incident turbulence. The turbulence is assumed locally isotropic at each radius with its statistics parametrically dependent on the radius. The unsteady aerodynamic response is based on a 
strip-wise description that relates the OGV unsteady pressure distribution at each radial location to the incident wake turbulence. The underlying unsteady response is the same as that used for tone calculation [18]. The resulting Quasi$3 \mathrm{D}$ distribution of the expected values of vane unsteady pressure field are then related to the estimates of the modal power via the classical Green's function formulation. The end results is the mode power level spectral density, $P_{m n}(\omega)$, which in short-hand notation may be written as

$$
P_{m n}(\omega)=\int_{r_{H}}^{r_{T}} \mid C_{m n}(r, \omega)^{2} \phi_{m n}^{2}(r) \Psi(r, \omega) d r
$$

where $C_{m n}$ is the chordwise integral of the unsteady pressure distribution at each radius, $\phi_{m n}$ the annular duct mode shape, and the function $\Psi$ is related to spectrum of the incident turbulence.

It should be pointed out that in deriving Eq. (1), the OGV is modeled as an ensemble of zero thickness flat plates in an infinite hard-wall annular duct containing a uniform axial mean flow. The parameters controlling the aerodynamic response are the absolute Mach number of the mean flow and vane chord, vane count and stagger angles at each radius (i.e., strip). In particular, in this work, the vane cascade stagger angle at each radius is defined as a weighted average of the airfoil section camber line with the leading edge receiving more weight as compared to the trailing edge in recognition of the fact that high-frequency response of the vane is concentrated near the leading edge. In addition to the aero input, the noise calculations also require the r.m.s. amplitude of the upwash turbulent fluctuations and integral length scales of turbulence in the axial, tangential and radial directions. Implicit in the derivation of Eq. (1) is the additional assumption that the radial integral scale is small compared with the span of the vane. Furthermore, the circumferential distribution of the turbulence intensity is taken to be of the form

$$
u^{\prime}(\xi, r)=u_{\mathrm{b}}^{\prime}(r)+u_{w}^{\prime}(r) e^{-\xi^{2} / L_{w}^{2}}
$$

where $u_{b}^{\prime}$ and $u_{w}^{\prime}$ are the background and wake turbulence intensities at each radial strip, and $\xi$ is the distance across one blade pitch measured in the direction normal to the mean wake centerline. The parameter $L_{w}$ will be defined shortly. $u_{b}^{\prime}$ and $u_{w}^{\prime}$ are computed from the CFD solution via

$$
u^{\prime}=(2 k / 3)^{1 / 2}
$$

where $k$ is the computed local turbulence kinetic energy of turbulence. Eq. (2) is in excellent agreement with the pitch-wise distribution of computed intensity. $L_{w}$ is chosen to be an integral length which multiplied by $u_{w}^{\prime}$ equal to the area contained under the computed profile (Figure 7). The distribution described by Eq. (2) is assumed to apply to all fan blade passages so that the pattern repeats around the annulus. Note that, this does not mean that the instantaneous turbulent fluctuations are the same for corresponding points in passages, but only their statistics. The same argument of course applies to the length scales. The length scales are estimated from the computed RANS flowfield solutions via

$$
\ell=\bar{k}^{3 / 2} / \bar{\varepsilon}
$$

where $\bar{k}$ and $\bar{\varepsilon}$ are the circumferentially averaged turbulence kinetic energy and dissipation rate. Defined in this manner, $\ell$ is the average size of the largest energy containing eddies in the flow. The parameter $\ell$ represents the longitudinal and $\ell / 2$ the lateral integral length scales of the incident turbulence (i.e., the isotropic assumption).

The variations (as a functions of radius) of the local Mach number, vane stagger angle, incident turbulence intensity and integral length scales, and the effective width of the intensity profiles are inputs for noise spectra computations. For each case considered in this work, this information was extracted from the corresponding CFD solution.

\section{Measured Noise Spectra for Comparisons}

Farfield noise spectra were measured for all three OGV configurations as a function of fan tip speed (see Ref. 12). Using an acoustically treated 
"barrier" wall, the contributions of the inlet and exhaust noise to the farfield spectra could be separated experimentally.

Additionally, since the model fan could be run in a "rotor-alone" configuration (see Ref. 11), it is also possible to isolate the contribution of OGV noise by subtracting the rotor-alone contribution from the rotor plus stator contribution on a power basis (see Figure 8). Figure 8a shows measured spectrum of total acoustic power (inlet plus exhaust) for rotor-stator combination from which rotor-alone contribution is subtracted to get the OGV power level. Figure $8 \mathrm{~b}$ shows the use of the measurements with the barrier wall (which blocks the exhaust radiation reaching the inlet). Here again, rotor-stator combination and rotor-alone spectra are available. This enables the separation of OGV inlet noise spectrum. Subtracting the inlet contribution from the inlet plus exhaust spectrum for OGV in Figure 8a, the exhaust spectrum of OGV alone is obtained (see Figure 8c). In practice, however, that proved problematic for all but the approach condition, since at high fan tip speeds, the rotor-alone levels tend to be higher than the stage (i.e., rotor plus stator) levels. Furthermore, since the current noise model does not account for the swirl between the rotor and stator or the transmission loss effects through the rotor, inlet noise predictions do not reflect the correct physics and as such are not suitable direct for comparisons with data.

Therefore, the data-theory comparisons are restricted to the exhaust noise at the approach speed only. However, predicted trends with the fan tip speed for both the inlet and exhaust at the three speeds are presented.

\section{RESULTS AND DISCUSSION}

For all nine cases the inlet and exhaust duct acoustic power levels were computed for frequencies up to $50 \mathrm{KHz}$. This range corresponds approximately from $0.5 \mathrm{BPF}$ to $11 \mathrm{BPF}$ for takeoff, $0.5 \mathrm{BPF}$ to $13 \mathrm{BPF}$ for cutback, and $0.5 \mathrm{BPF}$ to $18 \mathrm{BPF}$ for approach.

The spectral calculations were typically done at $0.5 \mathrm{BPF}$ increments, since the number of cut-on modes that must be computed increases so rapidly that smaller frequency increments would have significantly increased the computational time. In the following figures, the symbols denote the frequency points at which the spectral calculations were actually performed and the lines through the symbols are curve fits to provide an idea of the spectral shapes.

It should be pointed out that, occasionally, the computed amplitude of the aerodynamic response of one of the strips would be inordinately large due to local cascade resonance condition. This, in turn, would lead to a "wild" point in the associated acoustic response. By slightly adjusting the aerodynamic input parameters, the resonance point could be avoided. However, in this paper the occasional wild point has been eliminated from the computed spectra. In a 3D response, such local resonance conditions would not occur.

\section{a. Comparisons with the measured spectra}

First, the data-theory comparison is presented in terms of the acoustic power spectra for the three stator configurations. Figures 9 through 11 show the predicted and measured spectra for the baseline 54 radial vanes, 26 radial vanes, and 26 swept vanes configuration, respectively. Note that the measured spectra contain blade passing frequency (BPF) tone harmonics. While the BPF tone is cutoff (absent) for the baseline case, it is cut-on (present) for the other two cases. The current predictions have only the broadband noise component. The predicted shape of the spectra is in fairly good agreement with the measured spectra including the high frequency fall off. However, there is an under-prediction of levels, which may arise from several factors. The main one is the fact that the measurements may have contributions from additional noise sources while the predictions account for only the wake turbulence. Also, at high frequencies quadrupole noise may become important, as discussed by Mani et al. [19], and should be included to improve the prediction.

\section{b. Effect of fan tip speed on acoustic power spectra}

The variation of acoustic power with fan tip speed is shown for the 54 radial vane configuration in Figures 12 and 13. The figures show inlet and 
exhaust acoustic power spectra for the three tip speeds of interest. The spectra show the expected trend with the tip speed.

\section{c. Inlet and exhaust noise spectra}

The computed inlet and exhaust acoustic power spectra are compared in Figure 14 for the 54 radial stator vane configuration at takeoff condition. The inlet noise is substantially lower than that of the exhaust as observed in the wind tunnel measurements.

\section{d. Variation of noise with vane number}

As the vane count is reduced, the rotor-wake turbulence generated broadband noise is expected to reduce substantially. The cut-on fan design is expected to produce less broadband noise than the cut-off design to counteract the cut-on tone levels.

Figures 15 and 16 show inlet and exhaust power spectra for 54 radial vane and 26 radial vane configurations at approach. The acoustic power for 26 radial vanes is substantially lower than for the 54 radial vanes configuration. The power is expected to vary as $10 \log N_{V}^{2}$ (see Ref. 9) where $N_{V}$ is the vane count. This should result in $6.3 \mathrm{~dB}$ reduction in power levels for the 26-vane OGV compared with the 54-vane OGV. The predicted reduction in power due to the reduction in vane number is higher than expected at high frequencies. At frequencies lower than $5.5 \mathrm{kHz}$, the noise levels produced by the two configurations are not significantly different probably because at low frequencies there are additional noise sources present, which are not modeled in the present theory. A similar trend was observed in Boeing broadband noise experiments (see Ref. 13).

\section{e. Effect of vane sweep}

Vane sweep has been found to result in substantial reduction in tone noise levels compared to the radial vane configuration [20]. Woodward (see Ref. 12) found that the vane sweep reduces, in addition, the broadband noise by one to two decibels at certain speeds. The measured spectra for the approach exhaust radiation show (see Figure 17) a small reduction in noise level in the low frequency range $(<10 \mathrm{kHz})$ due to vane sweep. It should be emphasized that if tones are removed from the measured spectra the reduction will be even smaller. The predictions do not show any decrease in acoustic power levels for the 26 swept geometry compared to the 26 vane radial (see Figure 18).

\section{f. Acoustic power as a function of mode order $m$}

Figure 19 shows the inlet and exhaust acoustic power as function of circumferential mode $m$ order for frequencies from $3 \mathrm{BPF}, 5 \mathrm{BPF}$ and $7 \mathrm{BPF}$. The number of cut-on circumferential mode orders $(m)$ and the number of cut-on radial mode orders $(n)$ in each m-order increase linearly with frequency (see Figure 20). In general, the peak acoustic power level reduces with increases in frequency. At frequencies higher than 5BPF, the fall off with increasing $m$ order is higher for the positive $m$ orders than for negative $m$ orders.

\section{g. Cutoff ratio and acoustic power}

Sometimes it is helpful to look at the acoustic power radiated as a function of cutoff ratio and that is particularly done in design and tradeoff studies [21]. Figure 21 shows the variation of acoustic power as a function of cutoff ratio for exhaust radiation at approach for two frequencies, 4BPF and 6BPF. The symbols denote different $m$ orders and five $n$ orders $(n=0-4)$ are included in the plot. Since no effect of flow swirl is included in the current model, the same number of co-rotating and contra-rotating modes are cut-on at each frequency. The acoustic power decreases sharply as the cutoff ratio is increased and eventually reaches nearly a plateau beyond a cutoff ratio of three for both frequencies.

\section{CONCLUDING REMARKS}

The rotor wake turbulence stator interaction broadband noise has been computed for representative fan operating conditions for three fan stage configurations. The computations employ the wake flow turbulence information from accurate computational fluid dynamic solutions. The predicted noise spectra show the observed trends with fan tip speed and vane count. The 
predicted acoustic power levels and shape of the spectra show reasonable agreement with the measured spectra for the exhaust noise at approach condition.

\section{REFERENCES}

1. Envia, E., "Fan Noise Reduction: An Overview," International Journal of Aeroacoustics, Vol. 1 No. 1, pp. 43-65, 2002.

2. Glegg, S.A.L. and Jochault C., "Broadband Self Noise from a Ducted Fan," AIAA Paper 971612, May 1997.

3. Gouville, B., Roger, M., Cailleau, J.M., "Prediction of Fan Broadband Noise," AIAA Paper 98-2317, 1998.

4. Morin, B.L., "Broadband Fan Noise Prediction System for Gas Turbine Engines," AIAA paper 99-1889, 1999.

5. Hanson, D.B., "Broadband Noise of Fans With Unsteady Coupling Theory to Account Rotor and Stator Reflection/Transmission Effects, NASA/CR—2001-21136, November 2000.

6. Podboy, G.G., Krupar, M.J., Helland, S.M., and Hughes, C.E., "Steady and Unsteady Flow Field Measurements within a NASA 22 Inch Fan Model," AIAA Paper 2002-1033, January 2002.

7. Adamczyk, J.J., Celestina, M.L., Beach, T.A., and Barnett, M., 1990, "Simulation of Threedimensional Viscous Flow within a Multistage Turbine," Tran. ASME, 112, 370-376.

8. Shih, T. H., Liou, W.W., Shabbir, A., Zhu, J., and Yang, Z., 1995, "A New $k-\varepsilon$ Eddy Viscosity Model for High Reynolds Number Turbulent Flows," Computers in Fluids, 24, 3, 227-238.

9. Ventres, C.S, Theobald, M.A., and Mark, W.D., "Turbofan Noise Generation Vol. 1: Analysis," NASA CR-167951, July 1982.

10. Hughes, C.E., "Aerodynamic Performance of Scale-Model Turbofan Outlet Guide Vanes
Designed for Low Noise," AIAA Paper 20020374, January 2002.

11. Hughes, C.E., Jeracki, R.J., and Miller, C.J., "Fan Noise Source Diagnostic Test - Rotor-Alone Nacelle Aerodynamic Performance Results," AIAA-Paper 2002-2426, June 2002.

12. Woodward, R.P., Hughes, C.E., Jeracki, R.J., and Miller, C.J., "Fan Noise Source Diagnostic Test - Farfield Acoustic Results," AIAA-Paper 2002-2427, June 2002.

13. Ganz, U.W., Joppa, P.D, Patten, T.J., and Scharpf, D.F., "Boeing 18-Inch Fan Rig Broadband Noise Test", NASA/CR-1998208704, September 1998.

14. Thorp, S.A., Trowbridge D., Bartos K.F., SABER - Structural Airfoil and Blade Engineering Routines, User Manual, June 1998, 104 pgs.

15. Theory Document, DT_NURBS Spline Geometry Subprogram Library Version 3.6, Craderock Division, Naval Surface Warfare Center, October 1998.

16. Users Manual, DT_NURBS Spline Geometry Subprogram Library, Version 3.6, Craderock Division, Naval Surface Warfare Center, October 1998.

17. Reference Manual, DT_NURBS Spline Geometry Subprogram Library, Version 3.6, Craderock Division, Naval Surface Warfare Center, October 1998.

18. Meyer, H.D. and Envia E., "Aeroacoustic Analysis of Turbofan Noise Generation,"

NASA/CR-4715, March 1996.

19. Mani, R, Gliebe, P.R., and Ho, P.Y., "Fan Broadband Noise Model Development," NASA CR-198457, December 1997.

20. Envia, E and Nallasamy, M., "Design Selection and Analysis of Swept and Leaned Stator Concept," Journal of Sound and Vibration, Vol. 228, pp. 793-836, 1999. 
21. Rice, E.J., "Broadband Noise Radiation Models for Aircraft Engines", Final Report, May 1998.

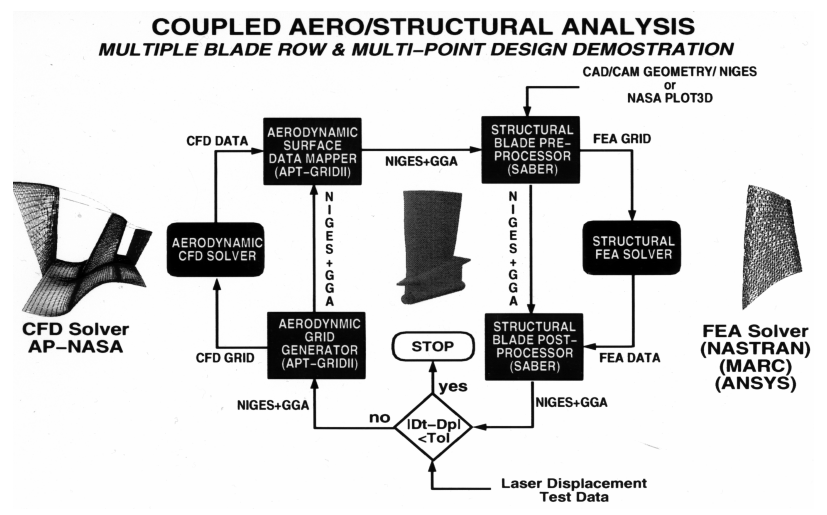

Figure 1. Outline of SABER system.

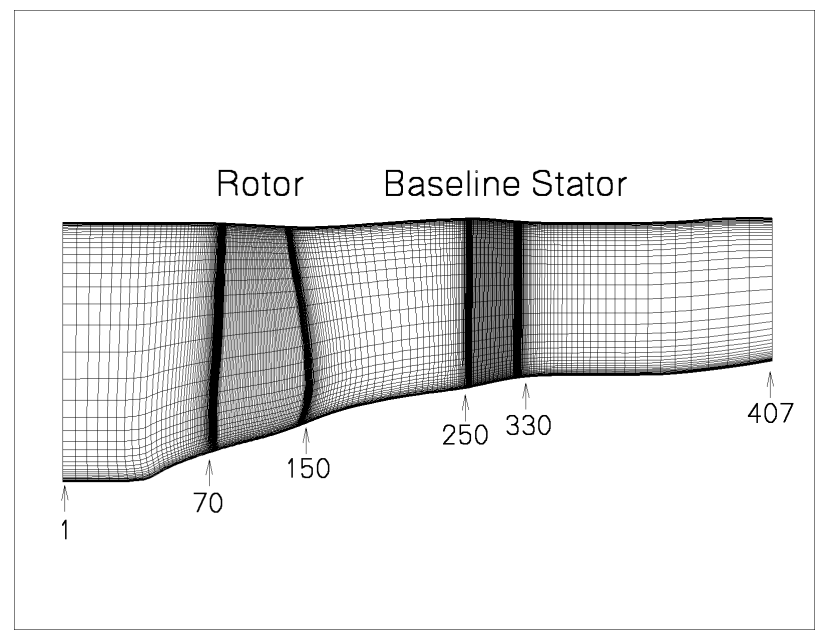

Figure 2. A meridional view of the computational mesh showing the rotor and baseline stator.

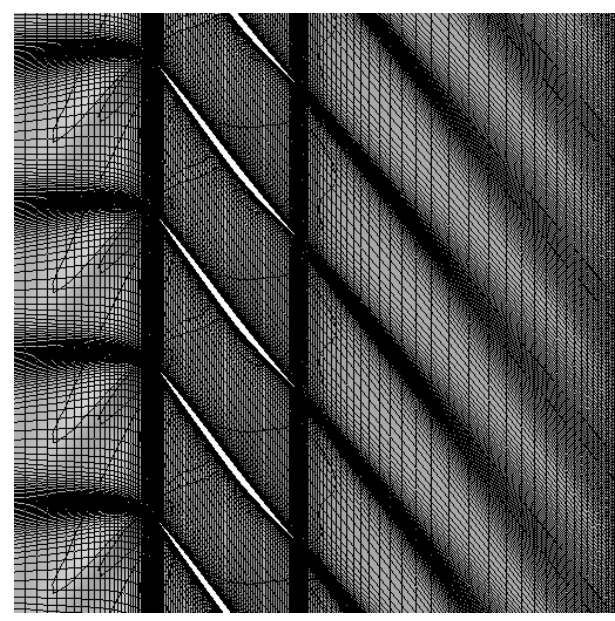

Figure 3. Blade-to-blade view of the mesh at midspan.

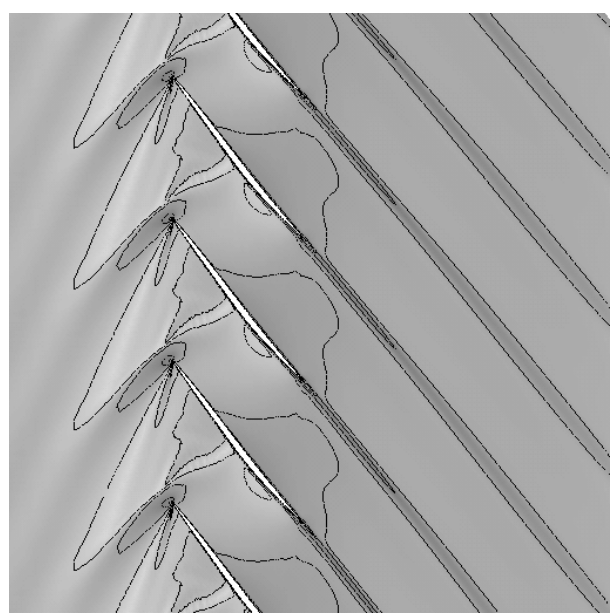

Figure 4. Contour lines of the axial velocity showing the blade wake evolution in the blade-to-blade plane at $75 \%$ span.

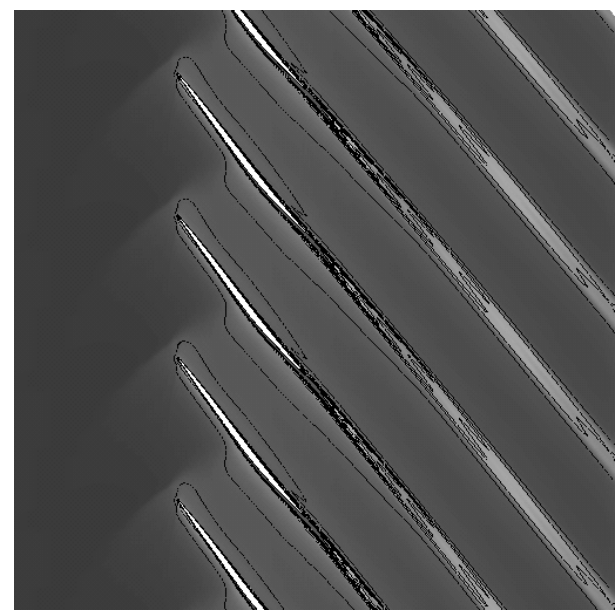

Figure 5. Contour lines of the turbulence kinetic energy at $75 \%$ span. 


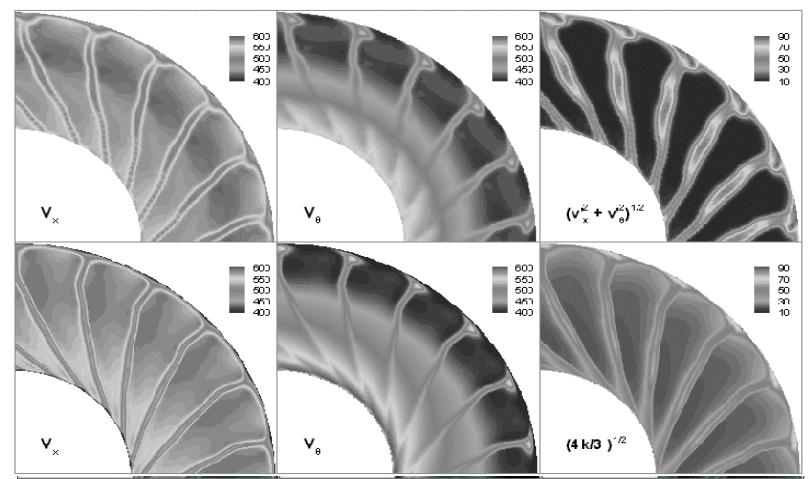

Figure 6. Comparison of experimental (top) and CFD (bottom) results for the baseline configuration at takeoff at 2 inches behind the rotor.

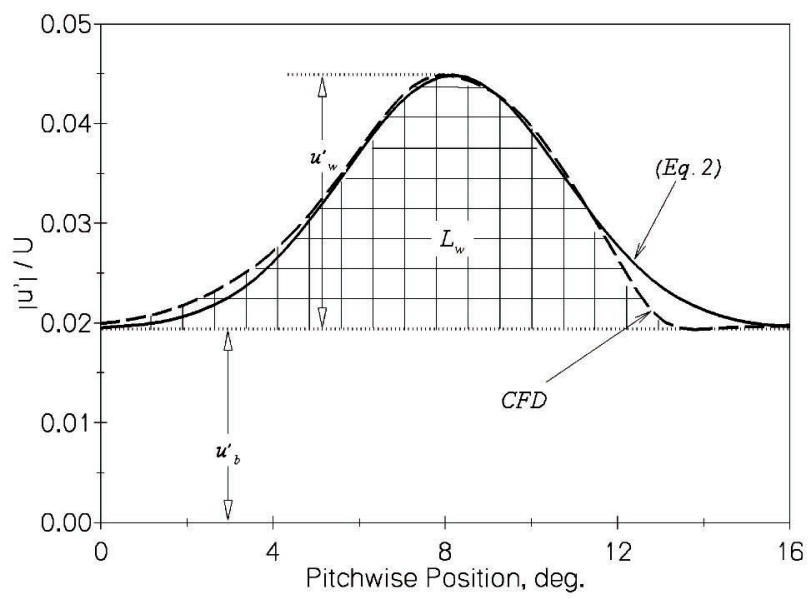

Figure 7. A representative turbulence intensity profile. Dashed line denotes the CFD solution and the solid line the fit using Eq. (2).
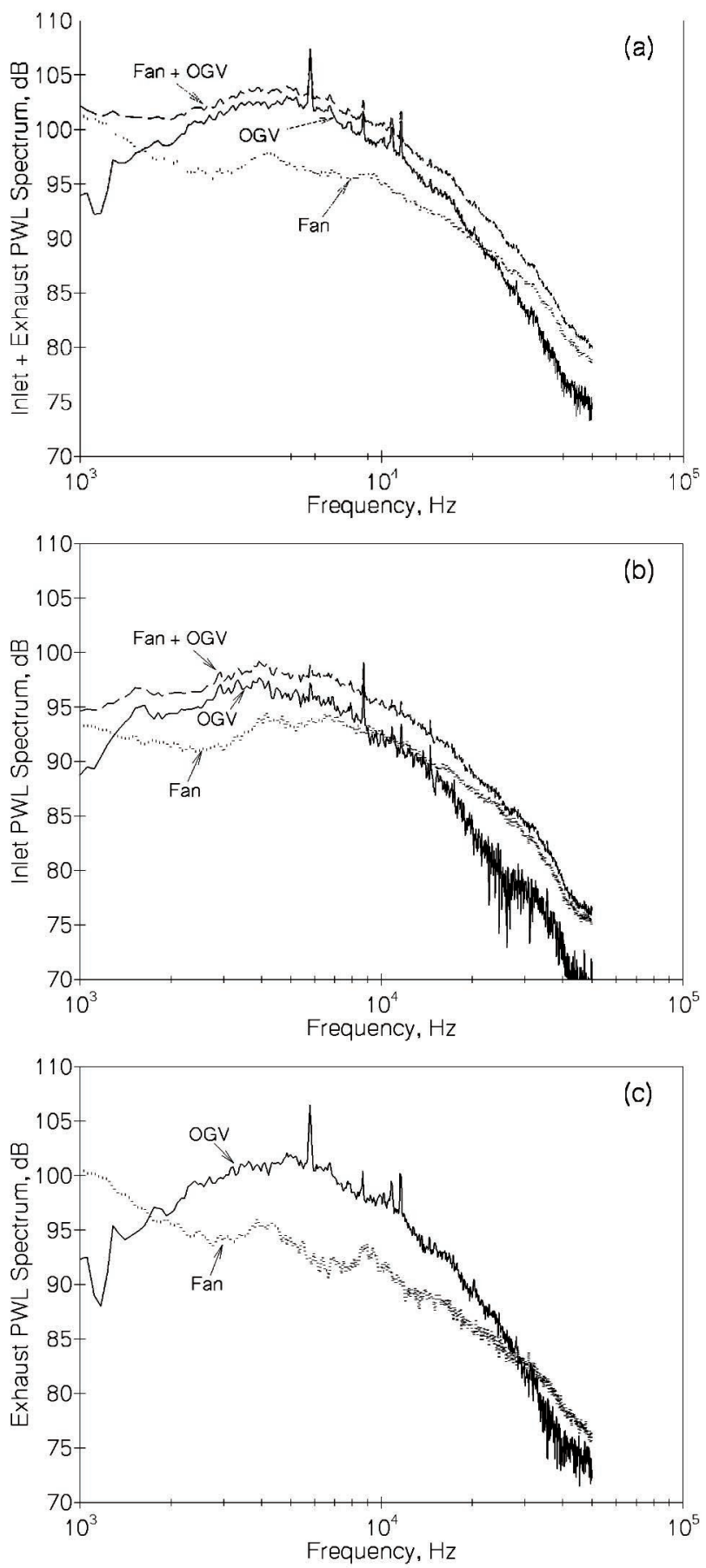

Figure 8. Separation of measured inlet noise from exhaust noise and rotor noise from stator (OGV) noise. Frames (a) through (c) show various stages of separation. Baseline: Approach. 


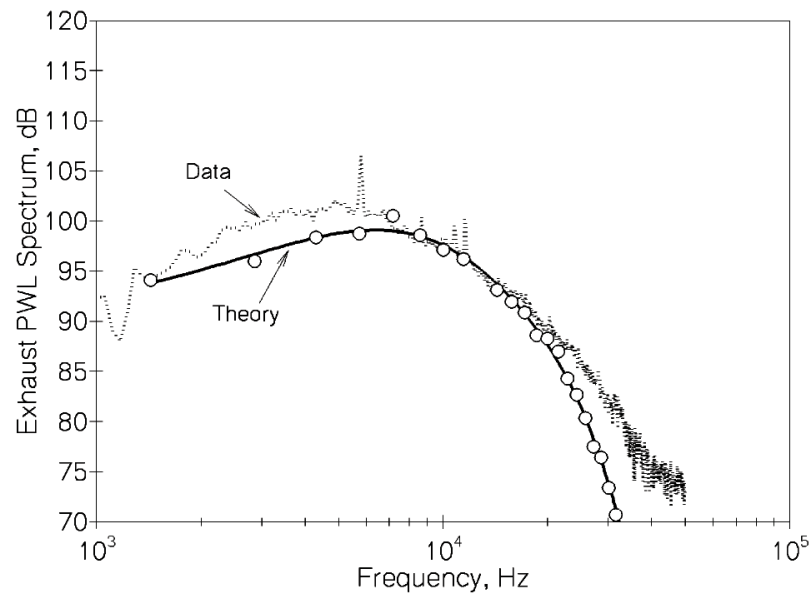

Figure 9. Comparison of computed and measured spectra for the baseline stator (54 radial vanes) at approach in the exhaust.

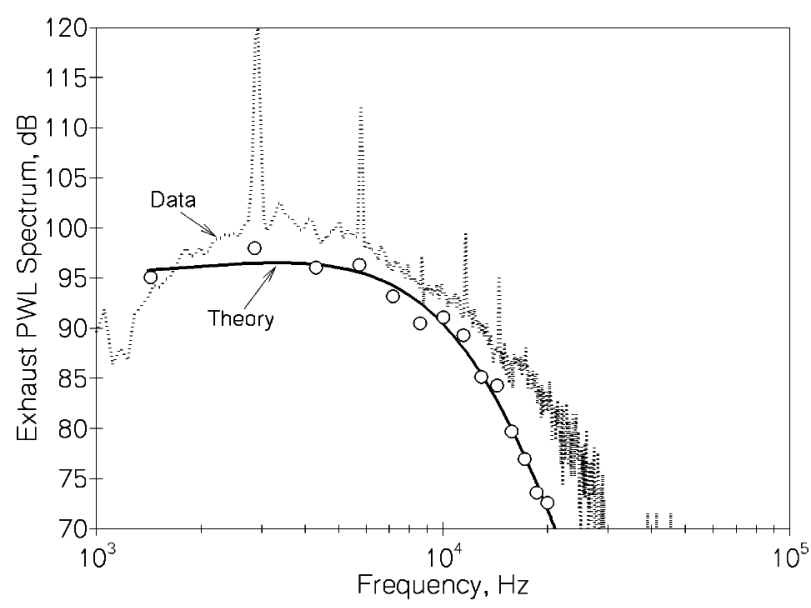

Figure 10. Comparison of computed and measured spectra for the low-count stator (26 radial vanes) at approach in the exhaust.

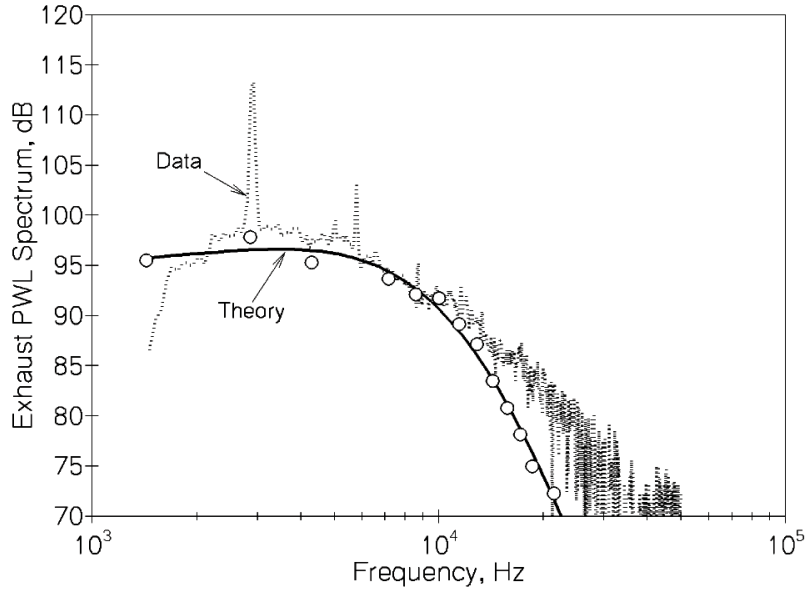

Figure 11. Comparison of computed and measured spectra for the low-noise stator (26 swept vanes) at approach in the exhaust.

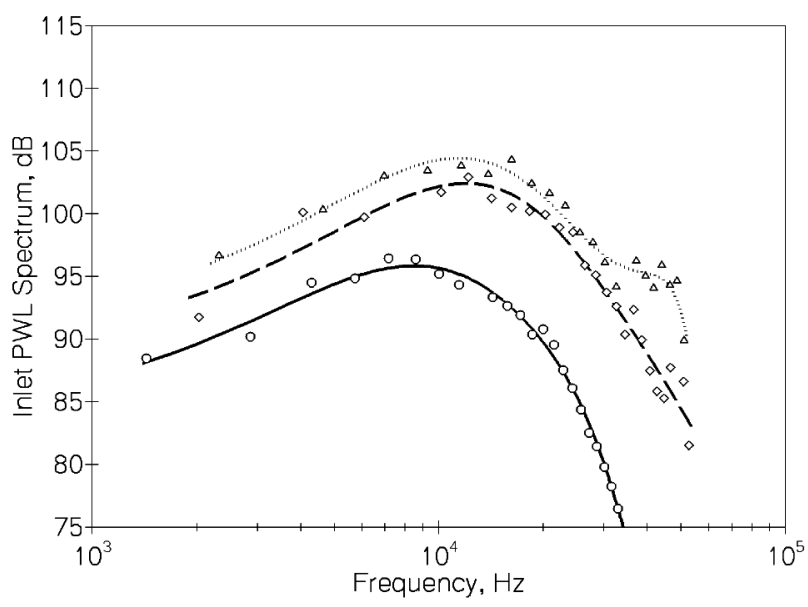

Figure 12. Effect of fan tip speed on inlet acoustic power spectrum for the baseline stator. Solid line: approach, dashed line: cutback, and dotted line: takeoff. 


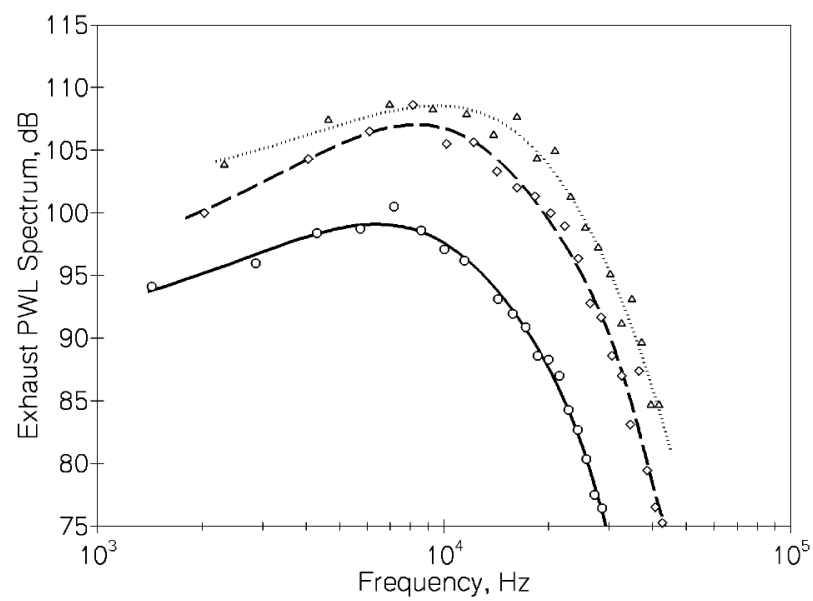

Figure 13. Effect of fan tip speed on exhaust acoustic power spectrum for the baseline stator. Solid line: approach, dashed line: cutback, and dotted line: takeoff.

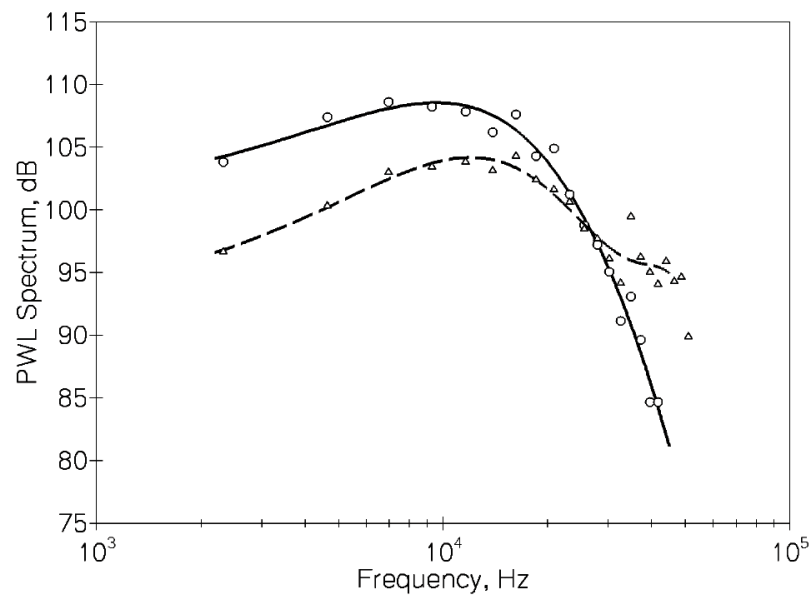

Figure 14. Inlet and exhaust power spectra comparisons for the baseline stator at takeoff. Solid line: exhaust, dashed line: inlet.

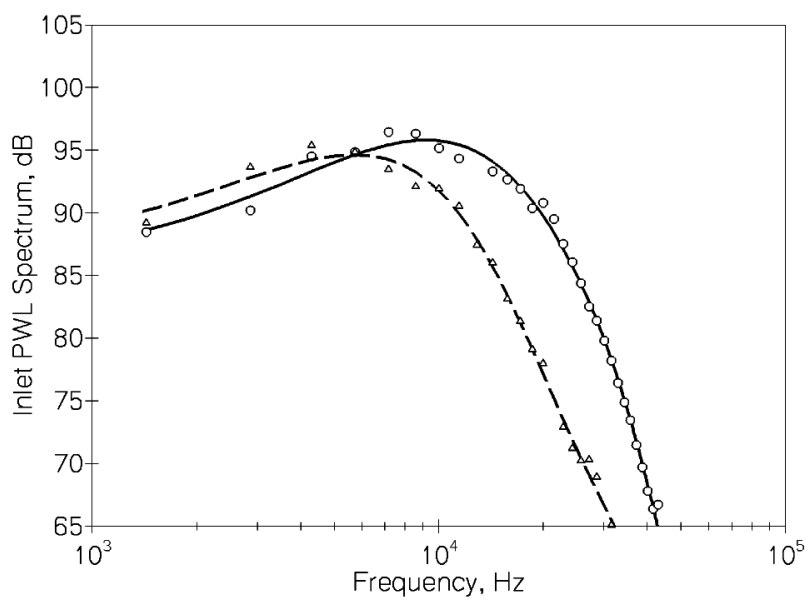

Figure 15. Effect of vane count on inlet acoustic power spectrum at approach. Solid line: 54-vane OGV, dashed line: 26vane OGV.

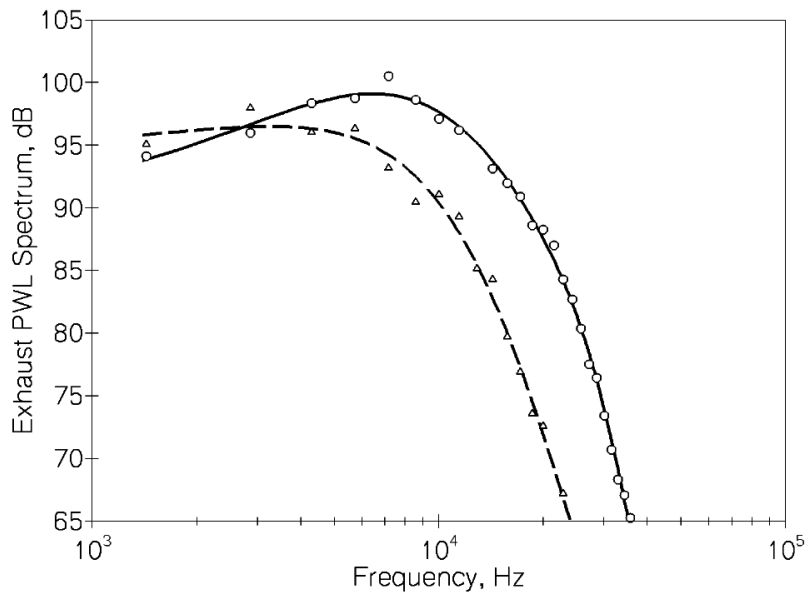

Figure 16. Effect of vane count on exhaust acoustic power spectrum at approach. Solid line: 54-vane OGV, dashed line: 26-vane OGV. 


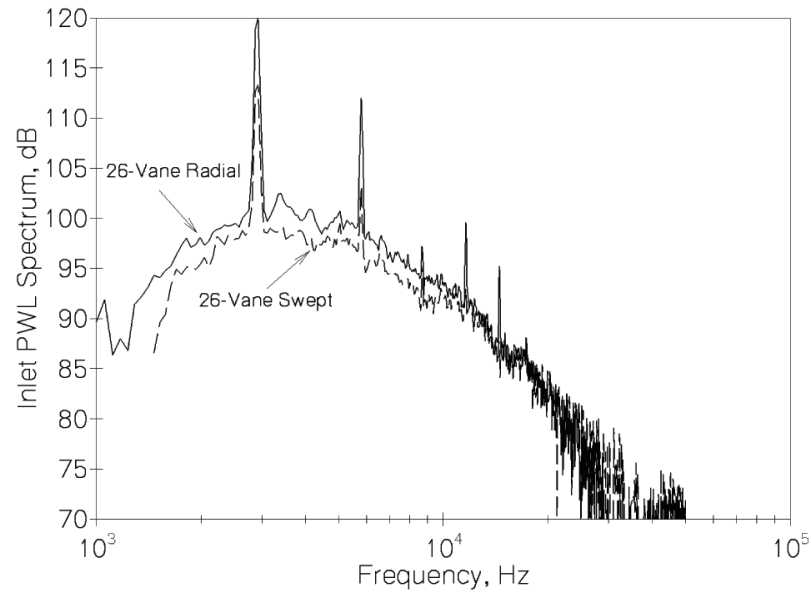

Figure 17. Measured effect of vane sweep on exhaust acoustic power spectrum at approach.

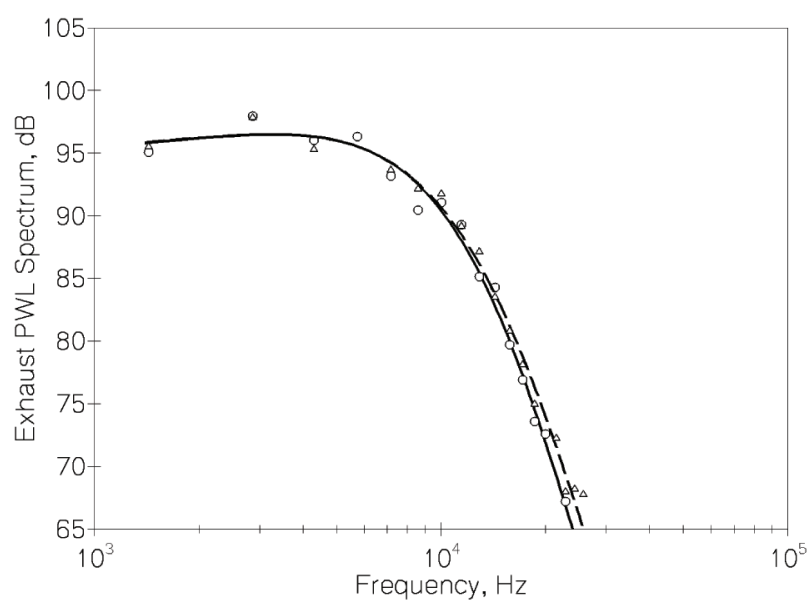

Figure 18. Predicted effect of vane sweep on exhaust acoustic power spectrum at approach. Solid line: 26-vane radial OGV, dashed line: 26-vane swept OGV.

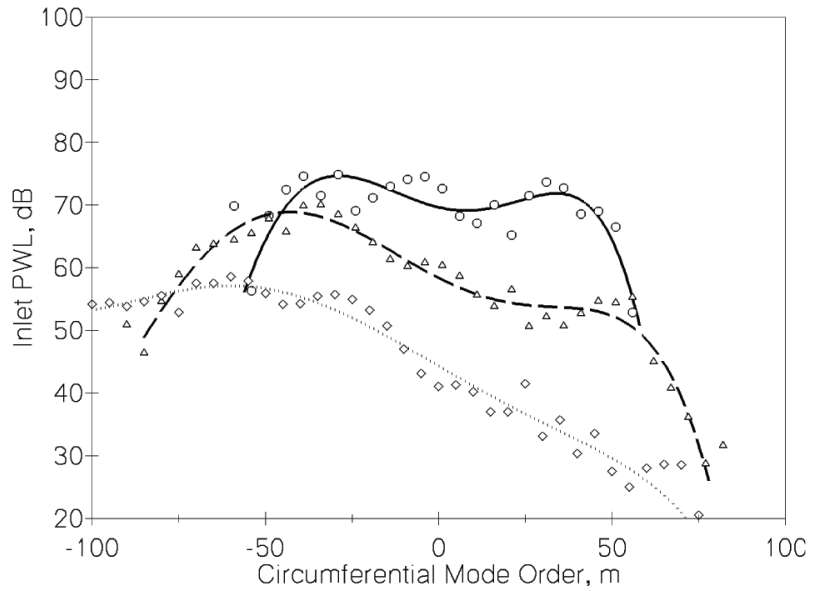

Figure 19. Inlet acoustic power distribution as a function of spinning mode order (m) for the baseline stator at approach. Solid line: 3BPF, dashed line: 5BPF, dotted line: 7BPF.

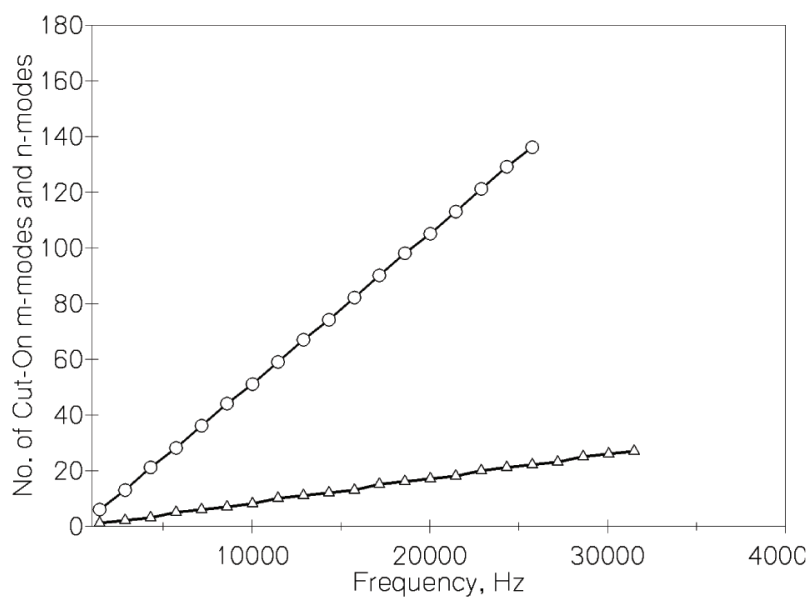

Figure 20. Variation of the number of cut-on modes with frequency. Circles: $m$ orders, triangles: $n$ orders. 


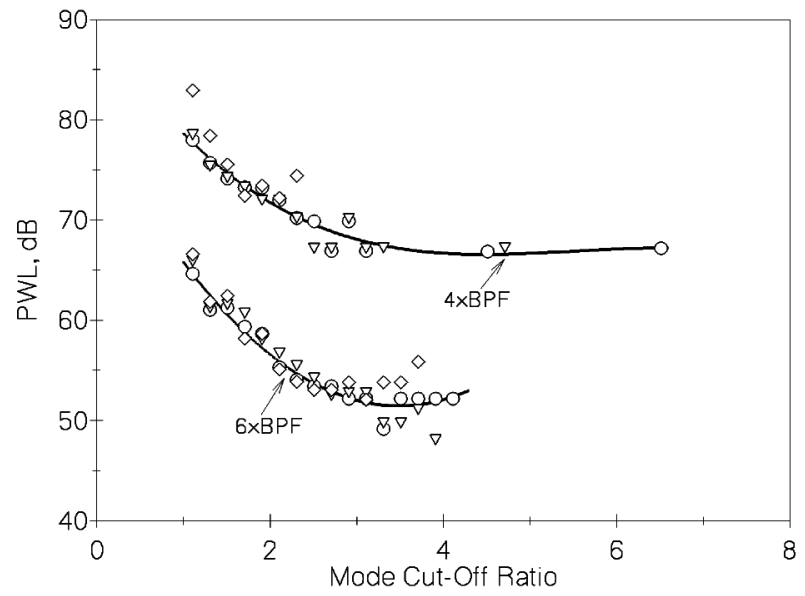

Figure 21. Inlet acoustic power as a function of cut-off ratio for the baseline stator at approach. 
Public reporting burden for this collection of information is estimated to average 1 hour per response, including the time for reviewing instructions, searching existing data sources, gathering and maintaining the data needed, and completing and reviewing the collection of information. Send comments regarding this burden estimate or any other aspect of this collection of information, including suggestions for reducing this burden, to Washington Headquarters Services, Directorate for Information Operations and Reports, 1215 Jefferson Davis Highway, Suite 1204, Arlington, VA 22202-4302, and to the Office of Management and Budget, Paperwork Reduction Project (0704-0188), Washington, DC 20503.

\begin{tabular}{|l|l|l}
\hline 1. AGENCY USE ONLY (Leave blank) & $\begin{array}{c}\text { 2. REPORT DATE } \\
\text { August } 2002\end{array}$ & $\begin{array}{r}\text { 3. REPORT TYPE AND DATES COVERED } \\
\text { Technical Memorandum }\end{array}$ \\
\hline
\end{tabular}

\section{TITLE AND SUBTITLE} 5. FUNDING NUMBERS

Fan Noise Source Diagnostic Test Computation of Rotor Wake Turbulence Noise

6. AUTHOR(S)

WU-781-30-11-00

M. Nallasamy, E. Envia, S.A. Thorp, and A. Shabbir

7. PERFORMING ORGANIZATION NAME(S) AND ADDRESS(ES)

National Aeronautics and Space Administration

John H. Glenn Research Center at Lewis Field

Cleveland, Ohio 44135-3191

8. PERFORMING ORGANIZATION REPORT NUMBER

E-13493

\section{SPONSORING/MONITORING AGENCY NAME(S) AND ADDRESS(ES)}

National Aeronautics and Space Administration

Washington, DC 20546-0001

10. SPONSORING/MONITORING AGENCY REPORT NUMBER

NASA TM-2002-211798

AIAA-2002-2489

11. SUPPLEMENTARY NOTES

Prepared for the Eighth Aeroacoustics Conference cosponsored by the American Institute of Aeronautics and Astronautics and the Confederation of European Aerospace Societies, Breckenridge, Colorado, June 17-19, 2002. M. Nallasamy, QSS Group, Inc., Cleveland, Ohio 44135; E. Envia and S.A. Thorp, NASA Glenn Research Center; A. Shabbir, University of Toledo, Toledo, Ohio. Responsible person, M. Nallasamy, organization code 5940, 216-977-1287.

12a. DISTRIBUTION/AVAILABILITY STATEMENT

12b. DISTRIBUTION CODE

Unclassified - Unlimited

Subject Category: 71

Distribution: Nonstandard

Available electronically at http://gltrs.grc.nasa.gov

This publication is available from the NASA Center for AeroSpace Information, 301-621-0390.

13. ABSTRACT (Maximum 200 words)

An important source mechanism of fan broadband noise is the interaction of rotor wake turbulence with the fan outlet guide vanes. A broadband noise model that utilizes computed rotor flow turbulence from a RANS code is used to predict fan broadband noise spectra. The noise model is employed to examine the broadband noise characteristics of the 22-inch Source Diagnostic Test fan rig for which broadband noise data were obtained in wind tunnel tests at the NASA Glenn Research Center. A 9-case matrix of three outlet guide vane configurations at three representative fan tip speeds are considered. For all cases inlet and exhaust acoustic power spectra are computed and compared with the measured spectra where possible. In general, the acoustic power levels and shape of the predicted spectra are in good agreement with the measured data. The predicted spectra show the experimentally observed trends with fan tip speed, vane count, and vane sweep. The results also demonstrate the validity of using CFD-based turbulence information for fan broadband noise calculations.

\section{SUBJECT TERMS}

Acoustics; Fan noise; Broadband noise; Computational fluid dynamics 15. NUMBER OF PAGES

19

\begin{tabular}{|c|c|c|}
\hline $\begin{array}{c}\text { 17. SECURITY CLASSIFICATION } \\
\text { OF REPORT } \\
\text { Unclassified }\end{array}$ & $\begin{array}{c}\text { 18. SECURITY CLASSIFICATION } \\
\text { OF THIS PAGE } \\
\text { Unclassified }\end{array}$ & $\begin{array}{c}\text { 19. SECURITY CLASSIFICATION } \\
\text { OF ABSTRACT } \\
\text { Unclassified }\end{array}$ \\
\hline
\end{tabular}

NSN 7540-01-280-5500

Standard Form 298 (Rev. 2-89) 

